\title{
The Role of North Africa in the Emergence and Development of Modern Behaviors: An Integrated Approach
}

\author{
Emilie Campmas • Emmanuelle Stoetzel • \\ Aicha Oujaa • Eleanor Scerri
}

Published online: 12 December 2017

C) Springer Science+Business Media, LLC, part of Springer Nature 2017

This special issue of African Archaeological Review, entitled "The Role of North Africa in the Emergence and Development of Modern Behaviors: an Integrated Approach," is the outcome of a session held at the 23rd Society of Africanist Archaeologists (SAfA) meeting held in Toulouse, France, from June 26 to July 2, 2016. The session was organized by Emilie Campmas, Emmanuelle Stoetzel, Aicha Oujaa, and Eleanor Scerri.

The special issue builds on a series of recent meetings and publications focusing on the same topic and region, such as the meeting "Modern Origins: A North African Perspective," organized by Jean-Jacques Hublin and Shannon McPherron at the Max Planck Institute in 2007 (Hublin and McPherron 2012), the session "Northwest African Prehistory: Recent Work, New Results and Interpretations" organized by David Lubell at the 21st SAfA meeting in 2012 in Toronto (Lubell 2014), and the session "Origins and Evolution of

E. Campmas $(\bowtie)$

TRACES-UMR 5608-CNRS, University of Toulouse, 2 Jean

Jaurès, Toulouse, France

e-mail: em.campmas@gmail.com

E. Stoetzel

HNHP UMR 7194-CNRS, Muséum National d'Histoire

Naturelle-UPVD-Sorbonne Universités, Paris, France

A. Oujaa

INSAP, Rabat, Morocco

E. Scerri

Research Laboratory for Archaeology and the History of Art, University of Oxford, Oxford, UK
Modern Human Behavior: A View from North Africa" organized by Abdeljalil Bouzouggar, Nick Barton, and Nabiha Aouadi during the UISPP conference at Burgos in 2014 (Mutri 2016).

The use of the term "modern behaviors" is today considered to be contentious, because it is based on a number of assumptions, including that (1) modern behaviors are associated with modern humans, (2) behavioral complexity evolves linearly with archaic to modern human forms, (3) features considered to be hallmarks of modern behavior derive from specific European archaeological records, and (4) the determination of features considered as either "modern" or "non-modern" can only be a matter of qualitative opinion. In addition, taphonomic issues complicate evaluation (e.g., Henshilwood and Marean 2003; Conard 2010; Roberts 2016). However, the aim of the present special issue is not to address this debate itself, but rather to furnish new data for future discussions on the topic. For these reasons, and for the sake of continuity, we continue to use the term "modern behaviors" in this issue.

Development of our session at the 23rd SAfA meeting in 2016 was motivated by recent advances in several disciplines, including anthropological, cultural, and environmental studies concerned with the importance of North Africa in understanding of the emergence, development, or decline of early and recent anatomically modern humans and associated innovations.

The African continent occupies a central position in discussions and debates concerning the emergence, 
timing, and development of modern behaviors. Although North Africa has yielded human remains associated with Middle and Later Stone Age industries (MSA and LSA, respectively) in well-established chronological contexts, this geographical area is often excluded from debates concerning the origin and subsequent evolution and dispersals of Homo sapiens, which have mainly focused on East and South Africa. The present volume aims to provide new answers from a North African perspective, enhanced by the recent discovery of human remains with Middle Stone Age technology at Jebel Irhoud, Morocco dating to $315 \mathrm{ka}$ by Richter et al. (2017), and attributed to an early stage of anatomically modern human evolution by Hublin et al. (2017). This volume opts for an integrated scientific approach to explore the significance of North Africa, combining symbolic, technological, anthropological, subsistence, paleontological, and chronological data from this region. This includes contributions covering environmental reconstructions, and faunal, anthropological, technological, and use-wear analyses. From a chronological point of view, the papers mainly focused on the MSA (especially the Aterian), as well as on the LSA (Iberomaurusian).

The session and the present issue also provide an opportunity to discuss the possible character of social and demographic relationships between North Africa and other African regions.

We dedicate this special issue to André Debénath, who greatly contributed to the knowledge of North African prehistory. Sadly, André Debénath passed away in June 2016, just a few days before the 23rd SAfA meeting. Thus, this issue begins with a dedication written by his colleagues, Roland Nespoulet and Mohamed Abdeljalil El Hajraoui.

This special issue includes six contributions. Two syntheses concern both microvertebrate records of the Pleistocene to the Holocene, and the North African Middle Stone Age (especially the Aterian). Broader analyses encompass the Témara-Rabat region of Morocco (with Pleistocene mollusk shell thanatocenosis, and ancient human remains of Quarry 10). Other contributions concern Aterian and Iberomaurusian technological analyses and use-wear data from Libya and Algeria.

Emmanuelle Stoetzel (HNHP-UMR 7194, MNHN, France), in her paper "Adaptations and Dispersals of Anatomically Modern Humans in the Changing Environments of North Africa: The Contribution of Microvertebrates," highlights the importance of microvertebrates to reconstructing the paleoclimatic and paleoenvironmental context of human occupations, but also their role in tracing movements of faunal and human populations, notably between North Africa, Western Europe, and other parts of the African continent.

Emilie Campmas (TRACES-UMR 5608, University of Toulouse 2 Jean Jaurès, France), with a paper entitled "Integrating Human-Animal Relationships into New Data on Aterian Complexity: A Paradigm Shift for the North African Middle Stone Age," provides a synthesis of the Aterian of northwestern Africa, and especially animal-human relationships. She shows that Aterian populations had a broad diet, for example including the consumption of both terrestrial and marine resources along the Moroccan Atlantic coast. Aterian populations have also used faunal remains for the production of tools and ornaments.

In their paper, entitled "The Pleistocene of Rabat (Morocco): Mollusks, Coastal Environments and $\mathrm{Hu}-$ man Behaviour," Amel Chakroun (Faculty of Sciences, Department of Geology, University of Tunis El Manar) et al. analyzed thanatocenosis mollusks dating to MIS 11,7 , and 5 from the North Atlantic coastal area of Morocco. Their results, combined with regional geomorphological data, provide new data on the paleoenvironments in this area and on mollusk species available for prehistoric human populations, especially MSA groups, both for consumption and ornaments.

Aicha Oujaa (INSAP, Morocco) et al., with an article entitled 'The Fossil Human from Rabat-Kébibat (Morocco): Comparative Study of the Cranial and Mandibular Fragments,' furnish new data on the skull fragments and mandible morphology of the ancient human from Kébibat Quarry (Rabat, Morocco). These analyses allow the revision of the position of the remains in a wider geographical and chronological range. Several morphological characteristics of the mandible exclude the Kébibat remains from modern human groups. However, features on the skull fragments are highly derived, and fit with those of modern humans. Thus, these remains present a mosaic of features showing the complexity of human evolution in Africa.

Serena Falzetti (LTFAPA Laboratory, Sapienza University of Rome, Italy) et al., explore technological perspectives through their paper, entitled "From Aterian Notch to Aterian Tang: How to Make a Technological Invention." Aterian technology is well known from its tanged or stemmed points. The authors argue that the 
tang for hafting purposes represents a significant technical innovation. Thanks to the use-wear analyses of notches from Djebel Gharbi's industries and experimental data, they suggest that the "notch" is a technomorpho-functional unit applied to several blanks and used for several activities. Notches alone or multiples on blanks create different tool morphologies. Thus, tangs could have derived from a new combination of notches, which would define or transform the shape of the tool.

Finally, Latifa Sari (CNRPAH, Algeria) and KyungJin Kim (HNHP-UMR 7194, MNHN, France) provide results concerning the "Lithic Economy and Specialized Activities among the Iberomaurusian Populations of Tamar Hat Rockshelter (Northeastern Algeria)." Lithic industries characteristic of the Early Iberomaurusian from this site contains "becs," a feature not identified from any other Iberomaurusian site in the Maghreb. Technological approaches combined with use-wear analyses and experiments suggest that "bec" tools were hafted and used for engraving hard bone. These results are in agreement with the zooarchaeological study, which notably highlighted that deer were both consumed and used for bone tool production. At Tamar Hat, the increasing "bec" production during the end of the Later Stone Age occurs earlier than in the European Magdalenian. This comparison raises the question of the spread of this technological innovation from North Africa to other geographical areas.

In conclusion, thanks to these multidisciplinary contributions, this special issue provides both new data and new avenues by which to explore the importance of North Africa in the emergence and development of modern behaviors.

Acknowledgements We would like to sincerely thank the organization committee of the 23rd SAfA meeting: François Bon,
Laurent Bruxelle, Benoit Chevrier, Els Cornelissen, Pierre de Maret, François-Xavier Fauvelle, Eric Huysecom, Alexandre Livingstone Smith, Anne Mayor, and Caroline Robion-Brunner. We are also grateful to the Editor-in-Chief of African Archaeological Review, Adria LaViolette, for having supported the publication of this special issue. We thank all the participants of session 8 , and especially authors who published their results here. Finally, we express gratitude to all those who reviewed the manuscripts of this issue and provided feedback for the authors.

\section{References}

Conard, N. J. (2010). Cultural modernity: Consensus or conundrum. Proceedings of the National Academy of Sciences of the United States of America, 117, 7621-7622.

Henshilwood, C. S., \& Marean, C. (2003). The origin of modern behavior: Critique of the models and their test implications. Current Anthropology, 44, 627-651.

Hublin, J.-J., \& McPherron, S. (2012). Modern origins: A North African perspective. New York: Springer.

Hublin, J. J., Ben-Ncer, A., Bailey, S. E., Freidline, S. E., Neubauer, S., Skinner, M. M., Bergmann, I., Le Cabec, A., Benazzi, S., Harvati, K., \& Gunz, P. (2017). New fossils from Jebel Irhoud, Morocco and the pan-African origin of Homo sapiens. Nature, 546, 289-292.

Lubell, D. (2014). Northwest African prehistory: Recent work, new results and interpretations. Quaternary International, $320,1-2$.

Mutri, G. (2016). Origins and evolution of modern humans behaviour: A view from North Africa. Quaternary International, 413, 2-4.

Richter, D., Grün, R., Joannes-Boyau, R., Steele, T. E., Amani, F., Rué, M., Fernandes, P., Raynal, J. P., Geraads, D., Ben-Ncer, A., Hublin, J. J., \& McPherron, S. P. (2017). The age of the hominin fossils from Jebel Irhoud, Morocco, and the origins of the Middle Stone Age. Nature, 546, 293-296.

Roberts, P. (2016). 'We have never been behaviourally modern': The implications of material engagement theory and metaplasticity for understanding the Late Pleistocene record of human behavior. Quaternary International, 405, 8-20. 